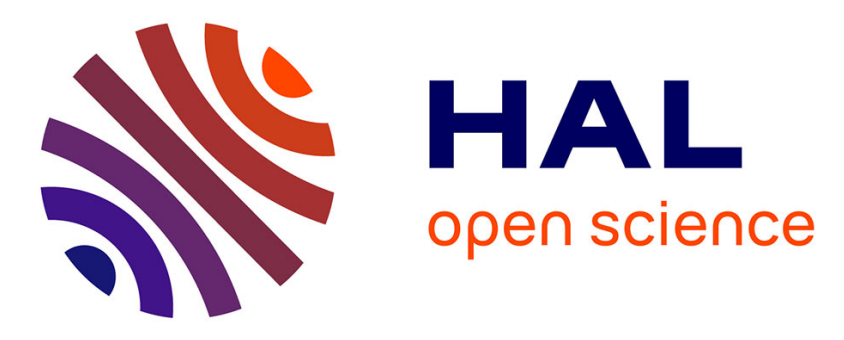

\title{
Echogenicity enhancement by end-fluorinated polylactide perfluorohexane nanocapsules: Towards ultrasound-activable nanosystems
}

Guilherme Picheth, Sophie Houvenagel, Camille Dejean, Olivier Couture, Rilton Alves de Freitas, Laurence Moine, Nicolas Tsapis

\section{To cite this version:}

Guilherme Picheth, Sophie Houvenagel, Camille Dejean, Olivier Couture, Rilton Alves de Freitas, et al.. Echogenicity enhancement by end-fluorinated polylactide perfluorohexane nanocapsules: Towards ultrasound-activable nanosystems. Acta Biomaterialia, 2017, 64, pp.313-322. 10.1016/j.actbio.2017.10.002 . hal-02324479

\section{HAL Id: hal-02324479 \\ https://hal.science/hal-02324479}

Submitted on 21 Oct 2019

HAL is a multi-disciplinary open access archive for the deposit and dissemination of scientific research documents, whether they are published or not. The documents may come from teaching and research institutions in France or abroad, or from public or private research centers.
L'archive ouverte pluridisciplinaire HAL, est destinée au dépôt et à la diffusion de documents scientifiques de niveau recherche, publiés ou non, émanant des établissements d'enseignement et de recherche français ou étrangers, des laboratoires publics ou privés. 
3 Guilherme Picheth ${ }^{\mathrm{a}, \mathrm{d}}$, Sophie Houvenagel ${ }^{\mathrm{a}}$, Camille Dejean $^{\mathrm{b}}$, Olivier Couture ${ }^{\mathrm{c}}$, Rilton Alves de 4

6

7

8 9

10

\section{Echogenicity enhancement by end-fluorinated polylactide perfluorohexane} nanocapsules: towards ultrasound-activable nanosystems

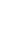

5

a Institut Galien Paris-Sud, CNRS, Univ. Paris-Sud, Université Paris-Saclay, 92296 Châtenay-Malabry, France.

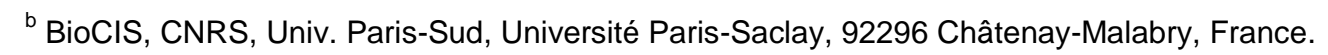

${ }^{\circ}$ Institut Langevin, ESPCI Paris, CNRS (UMR 7587), INSERM (U979), Paris, France

${ }^{\mathrm{d}}$ Biopol, Chemistry Department, Federal University of Paraná, 81531-980. Curitiba, PR, Brazil.

* Corresponding authors at: Institut Galien Paris-Sud, CNRS, Univ. Paris-Sud, Université Paris-Saclay, 92296 Châtenay-Malabry, France. E-mail address: laurence.moine@u-psud.fr (Laurence Moine), nicolas.tsapis@u-psud.fr (Nicolas Tsapis). 


\section{Abstract}

Polylactide (PLA) polymers containing five distinct lengths of fluorinated (from $\mathrm{C}_{3} \mathrm{~F}_{7}$ to $\mathrm{C}_{13} \mathrm{~F}_{27}$ ) and non-fluorinated $\left(\mathrm{C}_{6} \mathrm{H}_{13}\right)$ end-groups were successfully synthesized by ring-opening polymerization of $\mathrm{D}, \mathrm{L}$-lactide. Fluorination was expected to increase the encapsulation efficiency of perfluorohexane (PFH). $150 \mathrm{~nm}$ nanocapsules were obtained and ${ }^{19} \mathrm{~F}$ nuclear magnetic resonance revealed that nanocapsules formulated with fluorinated polymers increased by 2 -fold the encapsulation efficiency of $\mathrm{PFH}$ compared with non-fluorinated derivatives, without any effect of fluorine chain length. Fluorination of the polymers did not induce any specific in vitro cytotoxicity of nanocapsules towards HUVEC and J774.A1 cell lines. The echogenicity of fluorinated-shelled nanocapsules was increased by 3-fold to 40fold compared to non-fluorinated nanocapsules or nanoparticles devoid of a perfluorohexane core for both fundamental and harmonic ultrasound imaging modalities. In particular, an enhanced echogenicity and harmonic response was observed as the fluorinated chain-length increased, probably due to an increase of density and promotion of bubble nucleation. When submitted to focused ultrasound, both intact and exploded nanocapsules could be observed, also with end-group dependency, indicating that PFH was partly vaporized. These results pave the way to the design of theranostic perfluorohexane nanocapsules co-encapsulating a drug for precision delivery using focused ultrasound.

Keywords: Nanocapsules, perfluorohexane, fluorinated polymers, ultrasound imaging, focused ultrasound, fluorous interactions; cell viability. 


\section{Introduction}

Ultrasound contrast agents (UCAs) are efficient intravascular echo-enhancers currently indispensable to safe and accurate diagnosis of many diseases, including kidney cists [1], acute myocardial ischemia [2] and solid tumors [3]. All the commercially available UCAs, such as Definity ${ }^{\circledR}$ and Sonovue ${ }^{\circledR}$, are microbubbles constituted by a perfluorinated gaseous-core stabilized by a monolayer of phospholipids [4]. Unfortunately, the imaging and therapeutic applications of such materials are severely limited by (1) the fast-diffusing gas component, responsible for a relatively short distribution half-life in the bloodstream ( 60s after bolus injection) and an elimination half-life of about 6 minutes [5, 6], and (2) their inherent micrometer size range that prevents extravasation into solid tumors.

To overcome these limitations, research has focused on nanosystems that can be more stable and are able to diffuse beyond the vascular compartment. Since gas nanobubbles are difficult to stabilize [7], the strategy has consisted in encapsulating liquid perfluorocarbons (PFCs) into nanoemulsions using surfactants or in polymer nanocapsules [8]. Although interesting, this approach leads to a significant reduction of the echogenicity. Indeed, as the scattering cross section of a particle is defined according to equation 1 , a reduction of size and the replacement of the gas core by a liquid one, induce a decrease of the scattering cross section and subsequently of echogenicity.

$$
S C S=\frac{4 \pi}{9} k^{4} R^{6}\left[\left(\frac{\kappa_{d}-\kappa}{\kappa}\right)^{2}+\frac{3}{4} \frac{\left(\rho_{d}-\rho\right)^{2}}{\left(\rho_{d}+\rho\right)^{2}}\right], \text { Eq. } 1
$$

where $k$ is the wavenumber, $R$ is the radius of the particle, $\kappa_{d}$ and $k$ the compressibilities of respectively the particle and the medium, $\rho_{d}$ and $\rho$ the densities of respectively the particle and the medium [9].

To provide strong and long-lasting ultrasonic echoes, liquid PFCs of low boiling point, such as perfluorohexane (PFH) or perfluoropentane, have been selected for their ability to experience a liquid-to-gas transition once exposed to high acoustic pressures [10]. During this phenomenon - known as acoustic drop vaporization (ADV) - the PFC vapor phase undergoes oscillations around an equilibrium radius, which enhances the ultrasound scattering intensity of nanometric systems by several orders of magnitude [11-16]. An advantage of nanocapsules over microbubbles is their ability to co-encapsulate a drug for further therapeutic use [17]. As previously reported, PFC-containing nanocapsules can preserve their integrity and initial diameter after intravenous administration and passively accumulate in tumor tissues through the enhanced permeability and retention effect (EPR) [17-20] provided this effect occurs in patients [21]. After reaching tumor tissue, the release of 
a co-encapsulated drug might be triggered by focused ultrasound (FUS), causing local PFC cavitation/vaporization and may be followed by capsule shell rupture with subsequent drug release [22]. This strategy is currently investigated to deliver higher drug concentrations in the tumor vicinity and increase the chemotherapy efficacy while avoiding unwanted toxicity to healthy cells [23]. As FUS is clinically employed to ablate and eradicate tumor cells, particularly in prostate [24] and hepatocellular carcinomas [25], it represents an ideal trigger for drug delivery because it is a non-invasive technique, safe to adjacent tissues and provides a precise spatiotemporal control over the thermal and mechanical energy dissipation [26].

Before pushing forward these theranostic applications, the efficient encapsulation of low boiling point PFCs is required. Contrary to high boiling point PFCs such as perfluorooctylbromide, the entrapment of low boiling point PFCs such as $\mathrm{PFH}$ into polymeric nanosystems is a challenging process due to their fluorophilic character and high vapor pressure $[27,28]$. Perfluorinated compounds are usually immiscible with hydrophilic or hydrophobic solvents due to favored interactions between fluorinated domains [29]. Accordingly, perfluorinated liquids tend to phase-separate, resulting in low encapsulation efficiencies - from 3 to $9 \%$ in nano-sized formulations [30, 31] - which represents a limitation for ultrasound imaging and ultrasound-triggered drug delivery. To promote better PFH encapsulation into nanocapsules, we have synthesized polylactide (PLA) polymers terminated by linear fluorinated end-groups of distinct lengths. The presence of the fluorinated moiety is expected to increase PFH encapsulation efficiency by playing on fluorous-fluorous interactions as it was observed for another PFC: perfluorooctyl bromide [32]. Polymer synthesis, nanocapsule formulation and characterization are reported. Finally, the nanocapsule echogenicity and ability to be destroyed by focused ultrasound is evaluated. 


\section{Materials and Methods}

\subsection{Materials}

D,L-lactide was purchased from Polysciences (Germany) and perfluorohexane (purity $>98 \%$ ) was acquired from Alfa Aesar (Germany). 1-hexanol from Acros Organics (Belgium), 2,2,3,3,4,4-heptafluoro-1-butanol, $1 \mathrm{H}, 1 \mathrm{H}$ perfluoro-1-heptanol, $1 \mathrm{H}, 1 \mathrm{H}$ perfluoro1-nonanol, $1 \mathrm{H}, 1 \mathrm{H}$ perfluoro-1-dodecanol and $1 \mathrm{H}, 1 \mathrm{H}$ perfluoro-1-tetradecanol were acquired from Fluorochem (United Kingdom). Acetone, tetrahydrofuran (THF) and dichloromethane were purchased from Carlo Erba Reactifs (France), chloroform and diethyl ether from VWR (France). Stannous octoate, dry toluene, $\mathrm{D}_{2} \mathrm{O}$, sodium cholate, trifluoroacetic acid (TFA) and polyvinyl alcohol (PVA, 30-70kDa, 87-90\% hydrolyzed) were provided by Sigma-Aldrich (France). Deuterated solvents ( $\mathrm{CDCl} 3$ and acetone-d) were purchased from Eurisotop (France), Cell culture reagents such as DMEM (Dulbecco's modified Eagle's medium), RPMI 1640 (Roswell Park Memorial Institute medium), FBS (Fetal Bovine Serum), trypsinEDTA solution and PBS ( $\mathrm{Ca}^{2+}$ and $\mathrm{Mg}^{2+}$ free phosphate buffer) were purchased from Sigma Aldrich (France). The ultrapure water was produced by a Millipore Synergy 185 apparatus coupled with a RiOs5 ${ }^{\mathrm{TM}}$ (Millipore, France) with a resistivity of $18.2 \mathrm{M} \Omega . \mathrm{cm}$. The NMR sample tubes and coaxial inserts were obtained from CortecNet (France).

\subsection{Polymer Synthesis}

All fluorinated (PLA- $\mathrm{C}_{3} \mathrm{~F}_{7}, \mathrm{PLA}-\mathrm{C}_{6} \mathrm{~F}_{13}, \mathrm{PLA}-\mathrm{C}_{8} \mathrm{~F}_{17}, \mathrm{PLA}-\mathrm{C}_{11} \mathrm{~F}_{23}$ and PLA-C $\mathrm{C}_{13} \mathrm{~F}_{27}$ ) and non-fluorinated $\left(P L A-\mathrm{C}_{6} \mathrm{H}_{13}\right)$ derivatives of polylactide polymers were synthesized by ring opening polymerization (ROP) with the presence of stannous octoate as catalyst [33] [34]. All glassware and stir bars were flame-dried and cooled under argon flow. Briefly, in a 10 $\mathrm{mL}$ schlenck tube equipped with a magnetic stir-bar, the $\mathrm{D}$, L-lactide $(10.4 \mathrm{mmol}, 1.5 \mathrm{~g})$ and corresponding initiator $(0.075 \mathrm{mmol})$ - 1-hexanol for PLA- $\mathrm{C}_{6} \mathrm{H}_{13}, 2,2,3,3,4,4$-heptafluoro-1butanol for $\mathrm{PLA}-\mathrm{C}_{3} \mathrm{~F}_{7}, 1 \mathrm{H}, 1 \mathrm{H}$ perfluoro-1-heptanol for $\mathrm{PLA}-\mathrm{C}_{6} \mathrm{~F}_{13}, 1 \mathrm{H}, 1 \mathrm{H}$ perfluoro-1nonanol for PLA- $\mathrm{C}_{8} \mathrm{~F}_{17}, 1 \mathrm{H}, 1 \mathrm{H}$ perfluoro-1-dodecanol for PLA- $\mathrm{C}_{11} \mathrm{~F}_{23}$ or $1 \mathrm{H}, 1 \mathrm{Hp}-1$ tetradecanol for PLA- $\mathrm{C}_{13} \mathrm{~F}_{27}$ - were added to the flask under argon flow. The tube was sealed with a rubber cap and a stannous octoate solution $(0.05 \mathrm{mmol}, 20 \mathrm{mg})$ dissolved in 2 $\mathrm{mL}$ of dried toluene was added through the septum. The tube was purged with argon for $0.5 \mathrm{~h}$ and the polymerization reaction was conducted with continuous stirring at $130^{\circ} \mathrm{C}$ for 55 minutes in an oil bath under argon flow. The reaction was quenched by immersing the flask in a cold water bath. Afterwards, the solvent was evaporated under reduced pressure for $1 \mathrm{~h}$ and the material was dissolved in $5 \mathrm{~mL}$ of chloroform. The product was purified by precipitation as previously described [20]: all polymers were precipitated into cold diethyl ether $(80 \mathrm{~mL})$, next, PLA $-\mathrm{C}_{6} \mathrm{H}_{13}$ was dissolved into THF $(5 \mathrm{~mL})$, whereas the fluorinated 
polymers were dissolved in acetone $(20 \mathrm{~mL})$ and precipitated again in ultrapure water (150 $\mathrm{mL})$. The samples were freeze-dried for $24 \mathrm{~h}$ and a white powder was obtained. Lactide conversion $\geq 95 \%$ ( $\left.{ }^{1} \mathrm{H}-\mathrm{NMR}\right)$. ${ }^{1} \mathrm{H}-\mathrm{NMR}\left[400 \mathrm{MHz}, \mathrm{CDCl}_{3},{ }^{2} 5^{\circ} \mathrm{C}\right]$ PLA-C ${ }_{6} \mathbf{H}_{13}: \delta_{\mathrm{H}}$ 5.10-5.28 (PLA-CHCH $\mathrm{COO}_{3}$ ), 1.52-1.61 (- $\left.\mathrm{CCH}_{3}\right)$, 0.88-0.92 (- $\left.\mathrm{CH}_{2} \mathrm{CH}_{3}\right)$. PLA-C $\mathbf{F}_{3} \mathbf{F}_{7}$, PLA-C $\mathbf{F}_{6}$, PLA$\mathrm{C}_{8} \mathrm{~F}_{17}, \quad$ PLA-C ${ }_{11} \mathrm{~F}_{23}$ and PLA-C ${ }_{13} \mathrm{~F}_{27}: \delta_{\mathrm{H}}$ 5.10-5.28 (PLA-CHCH $\mathrm{CHO}_{3} \mathrm{CO}$ ), 4.50-4.70 ($\left.\mathrm{OCH}_{2} \mathrm{CF}_{2^{-}}\right), 1.52-1.61\left(-\mathrm{CCH}_{3}\right) .{ }^{19} \mathrm{~F}-\mathrm{NMR}\left[200 \mathrm{MHz}, \mathrm{CDCl}_{3}, 25^{\circ} \mathrm{C}\right] \mathrm{PLA}-\mathrm{C}_{3} \mathrm{~F}_{7}: \delta_{\mathrm{F}}-78.9$ to $79.05\left(-\mathrm{CF}_{3}\right),-118.5$ to $-119\left(-\mathrm{CH}_{2} \mathrm{CF}_{2^{-}}\right)$and -125.7 to $125.8\left(-\mathrm{CF}_{2} \mathrm{CF}_{2} \mathrm{CF}_{3}\right) ; \mathbf{P L A}-\mathrm{C}_{6} \mathrm{~F}_{13}$, PLA-C $_{8} F_{17}$, PLA-C $_{11} \mathbf{F}_{23}$ and PLA-C ${ }_{13} F_{27}:{ }^{19} \mathrm{~F}-\mathrm{NMR}\left[400 \mathrm{MHz}, \mathrm{CDCl}_{3}, 25^{\circ} \mathrm{C}\right]: \delta_{\mathrm{F}}-78.8$ to $79.05\left(-\mathrm{CF}_{3}\right),-117.6$ to $-117.9\left(-\mathrm{CH}_{2} \mathrm{CF}_{2}\right),-120.0$ to $-120.6\left(-\mathrm{CF}_{2} \mathrm{CF}_{2} \mathrm{CF}_{3}\right),-120.7$ to $-121.2(-$ $\left.\mathrm{CH}_{2} \mathrm{CF}_{2} \mathrm{CF}_{2}\right),-121.2$ to $-121.6\left(-\mathrm{CH}_{2} \mathrm{CF}_{2} \mathrm{CF}_{2} \mathrm{CF}_{2}\right)$ and -124.0 to $-124.5\left(-\mathrm{CF}_{2} \mathrm{CF}_{3}\right)$.

\subsection{Characterization}

All polymers were characterized by size exclusion chromatography (SEC) in chloroform at $30^{\circ} \mathrm{C}$ with a flow rate of $1 \mathrm{~mL} \cdot \mathrm{min}^{-1}$ by two columns (PL-gel $5 \mu \mathrm{m}$ MIXED-D $300 \times 7.5 \mathrm{~mm}$ ) calibrated against a curve based on poly(methyl methracrylate) standards (PMMA, Polymer Laboratories, Varian Inc.). The system was coupled to a refractive index detector (Spectrasystem RI-150, Thermo Electro Corp.). ${ }^{1} \mathrm{H}$ and ${ }^{19} \mathrm{~F}-\mathrm{NMR}$ spectra were obtained on a Bruker Advance $400 \mathrm{MHz}$ in $\mathrm{CDCl}_{3}$ at room temperature.

\subsection{Differential Scanning Calorimetry (DSC)}

All polymers were sealed in aluminum pans $(50 \mu \mathrm{L})$ and placed in a DSC apparatus (DSC Q1000, TA Instruments). All analyses were conducted under nitrogen flow $\left(20 \mathrm{~mL} \mathrm{~min}^{-1}\right)$ in a temperature range between 20 and $70^{\circ} \mathrm{C}$ at a heat and cooling rate of $20^{\circ} \mathrm{C} \cdot \mathrm{min}^{-1}$. The glass transition temperature was determined during the second heating run.

\subsection{Nanocapsules Formulation}

Nanocapsules (NCs) were prepared by the emulsion-evaporation technique, as previously described with modifications[19]. Briefly, $50 \mathrm{mg}$ of polymer was dissolved in 2 $\mathrm{mL}$ of chloroform in a $50 \mathrm{~mL}$ glass flask that was sealed with a rubber cap. Next, $30 \mu \mathrm{L}$ of PFH was introduced through the septum with constant stirring, and the media was emulsified with $10 \mathrm{~mL}$ of sodium cholate $1.5 \%(\mathrm{w} / \mathrm{w})$ at $4^{\circ} \mathrm{C}$ in a vortex for $1 \mathrm{~min}$. The mixture was then submitted to probe sonication (Branson digital sonifier, France) at $30 \%$ of maximal power for $1 \mathrm{~min}$ over ice. The solvent was evaporated by magnetic stirring at 300 RPM during $4 \mathrm{~h}$ in a thermostated bath at $20^{\circ} \mathrm{C}$. The samples were then filtered on $0.45 \mu \mathrm{m}$ PVDF filters (Whatman) and incubated with PVA $1 \% \mathrm{w} / \mathrm{w}$ for 5 days at $4^{\circ} \mathrm{C}$. Finally, they were centrifuged at $27.240 \mathrm{~g}$ (Optima LE-80K Ultracentrifuge Beckman Coulter, France) 
during $1 \mathrm{~h}$ at $4^{\circ} \mathrm{C}$ and the pellet was resuspended in $5 \mathrm{~mL}$ of ultrapure water to yield a final polymer concentration of $25 \mathrm{mg} \cdot \mathrm{mL}^{-1}$.

\subsection{Size and $\zeta$-potential}

The hydrodynamic diameter, polydispersity index $(\mathrm{Pdl})$ and zeta potential of nanocapsules were measured using a Zetasizer Nano ZS (Malvern, France) at $20^{\circ} \mathrm{C}$. All suspensions were diluted 1:10 in ultrapure water for size measurements and $1 \mathrm{mM} \mathrm{NaCl}$ for zeta potential measurements.

\subsection{Electron Microscopy}

Scanning electron microscopy was performed using a Merlin 6040 (Carl Zeiss, Germany) operating at $3 \mathrm{kV}$. The nanocapsules were deposited on carbon conductive double-sided tape (Euro-medex, France) and dried at room temperature. Afterwards, they were coated with a palladium-platinium layer of about $3 \mathrm{~nm}$ using a Cressington sputtercoater $208 \mathrm{HR}$ with a rotary-planetary-tilt stage, fitted with an MTM-20 thickness controller. Transmission electron microscopy (TEM) images were obtained in a JEOL 1400 (Jeol Ltd, USA) operating at $80 \mathrm{kV}$. All nanocapsules suspensions were diluted to a final concentration of $1 \mathrm{mg} / \mathrm{mL}$ polymer in ultrapure water and a $5 \mu \mathrm{L}$ droplet was deposited on a glow discharged carbon-coated 200 mesh grid. Negative staining was performed using $2 \%$ phosphotungstic acid (w/v). All images were acquired with an Orius camera (Gatan Inc, USA).

Cryo-Transmission Electron Microscopy (Cryo-TEM) images were performed using a JEOL 1400 TEM/STEM operating at $120 \mathrm{kV}$. NC suspensions at $50 \mathrm{mg} \cdot \mathrm{mL}^{-1}$ polymer were deposited $(5 \mu \mathrm{L})$ on a glow discharged carbon grid (Lacey 200 mesh), automatically blotted for $5 \mathrm{~s}$ and plunged into liquid ethane at $-175^{\circ} \mathrm{C}$ by a grid plunge freezer (Leica EM GP). The samples were kept in liquid nitrogen until analysis. Next, they were transferred to a pre-cooled cryo-TEM holder (Gatan 914) and observed under $10 \mathrm{pA} / \mathrm{cm}^{2}$ of luminosity, 2 $s$ of exposition and $-2 \mu \mathrm{m}$ of defocus. All images were acquired with a US1000XP camera (Gatan Inc, USA).

\subsection{PFH encapsulation efficiency}

For PFH quantification, $500 \mu \mathrm{L}$ of $\mathrm{NC}$ suspension freshly prepared was transferred to NMR tubes loaded with a stem coaxial insert containing TFA in $\mathrm{D}_{2} \mathrm{O}\left(12 \mu \mathrm{mol} . \mathrm{mL}^{-1}\right)$ as external standard [32, 35].Freeze-dried samples were also analyzed: $1 \mathrm{~mL}$ of freshly 
prepared nanocapsule suspension was freeze-dried during 24h employing an Alpha-1-2 LD apparatus (Christ, France). Afterwards, they were hermetically sealed with a rubber cap and stored at $-20^{\circ} \mathrm{C}$ until analysis. A total volume of $1 \mathrm{~mL}$ of chloroform then was introduced into the sealed tube by a needle, the suspension was vortexed ( 5 cycles of 30 seconds) and centrifuged at $0^{\circ} \mathrm{C}$ for 10 minutes at $1000 \mathrm{RPM}$. The organic solution was collected in a cold room at $4^{\circ} \mathrm{C}$ and introduced into an NMR tube loaded with the stem coaxial insert containing TFA in $\mathrm{D}_{2} \mathrm{O}\left(12 \mu \mathrm{mol} . \mathrm{mL}^{-1}\right)$. All spectra were obtained by a Bruker Avance 300 $\left(400 \mathrm{MHz}\right.$ ) operating at $4^{\circ} \mathrm{C}$. The total amount of encapsulated PFH was determined based on a PFH calibration curve. For each NC sample, the integration of the TFA peak at -76.5 ppm was determined as 3 and the resulting integration of the $\mathrm{PFH} \mathrm{CF}_{3}$ at -81.2 ppm was used to calculate the PFH concentration in the NMR tube based to the equation of the calibration curve.

\subsection{Cell viability}

The cytotoxicity of all NCs was evaluated in two distinct cell lines obtained from ATCC 206 (USA). Human endothelial umbilical vein cells (HUVEC) were cultivated in DMEM supplemented with $50 \mathrm{U} \cdot \mathrm{mL}^{-1}$ of penicillin, $50 \mathrm{U} \cdot \mathrm{mL}^{-1}$ of streptomycin and $10 \% \mathrm{FBS}$. Murine macrophage-monocytes (J774.A1cell line) were cultivated in RPMI 1640 medium supplemented with $50 \mathrm{U} \cdot \mathrm{mL}^{-1}$ of penicillin, $50 \mathrm{U} \cdot \mathrm{mL}^{-1}$ of streptomycin and $10 \%$ heat inactivated FBS. All cells were cultivated at $37^{\circ} \mathrm{C}$ at $5 \% \mathrm{CO}_{2}$ in a humidified atmosphere; they were splitted twice a week by trypsinisation for HUVEC and scraping for J774.A1. To assess the in vitro cytotoxicity, the MTT assay that evaluates the mitochondrial activity was employed [36]. A total volume of $100 \mu \mathrm{L}$ of the cells suspension was seeded into 96 well plates (TPP, Switzerland) at a concentration of $8 \times 10^{3}$ cells/well or $2 \times 10^{3}$ cells/well for 24 and $72 \mathrm{~h}$ of incubation, respectively. The cells were pre-incubated for $24 \mathrm{~h}$ and $100 \mu \mathrm{L}$ of a serial dilution of NCs $\left(1.0 \times 10^{-2}\right.$ to $\left.10 \mathrm{mg}^{-\mathrm{mL}^{-1}}\right)$ was added to the medium. After 24 or $72 \mathrm{~h}$ of incubation, $20 \mu \mathrm{L}$ of MTT solution at $5 \mathrm{mg} / \mathrm{mL}$ (3-(4,5-dimethylthiazol-2-yl)-2,5diphenyltetrazolium bromide) (Sigma, France) was added to each well. After 1 hof incubation, the medium was then aspired and replaced by $200 \mu \mathrm{L}$ of $\mathrm{mL}$ dimethylsulfoxide (ACS grade, BioBasic Inc, France). The absorbance $[A]$ was measured with a microplate reader (LAB Systems Original Multiscan MS, Finland) at $570 \mathrm{~nm}$ and the cell viability was calculated according to Eq. 2, where $[A]_{\text {control }}$ corresponds to the absorbance of untreated control cells: 


\subsection{In vitro Ultrasound Characterization}

Ultrasound images were acquired in a degassed water bath maintained at $37^{\circ} \mathrm{C}$ equipped with acoustic absorbing rubber. All NC were previously degassed and $0.8 \mathrm{~mL}$ were transferred to a silicone tube to a final $50 \mathrm{mg} \cdot \mathrm{mL}^{-1}$ suspension. Suspensions of Sonovue ${ }^{\circledR} 0.1 \%$, PVA $0.7 \%$ and nanoparticles (NP) produced with PLA- $\mathrm{C}_{8} \mathrm{~F}_{17}$ (without PFH) were used as controls. In vitro ultrasound imaging experiments were performed using an ultrafast programmable ultrasound scanner (Aixplorer, Supersonic Imagine, Aix-EnProvence, France). The scanner was equipped with a $5 \mathrm{MHz}$ linear array transducer (128 elements, $0.2 \mathrm{~mm}$ pitch) able to emit and accumulate a series of plane waves. The US focus was placed at the center of the silicone tube relative to the transducer at $3 \mathrm{~cm}$ depth. The pulse repetition frequencies used in this experiment was $50 \mathrm{~Hz}$. The images were obtained using a plane-wave B-mode sequence [37] at $0.1 \mathrm{MPa}$ peak negative pressure. Conventional focused B-mode (0.1 MPa) and contrast specific mode ( 0.2 MPa, executed by pulse inversion and amplitude modulation) images were initially performed for each sample independently. Imaging and monitoring pulses were 1 cycle long at $5 \mathrm{MHz}$. Finally, a disruption pulse was emitted ( 5 MPa peak negative pressure, 100 cycles long, which corresponds to $20 \mu \mathrm{s}$ ) and the imaging process was repeated, with $65 \mathrm{~B}$-mode images for the total $140 \mathrm{~ms}$ pulse sequence. Plane-wave images were acquired at a frame rate of 100 $\mathrm{Hz}$ and all data was transferred to a computer for analysis at Matlab (Mathworks, Natick, MA, USA). The backscattered intensity of the samples was obtained by averaging the power of the first and last image of the video in the region-of-interest (the silicone tube). The resulting intensities were subtracted by the backscattered intensity obtained with the tube filled with Milli-Q water.

Insert Figure 1 here

\subsection{Focused Ultrasound}

Focused ultrasound experiments were performed to assess the ability to destroy NCs. $100 \mu \mathrm{L}$ of $5 \mathrm{mg} \cdot \mathrm{mL}^{-1} \mathrm{NC}$ suspension were transferred to a 96 well microplate (OptiCell ${ }^{\circledR}$ ) that was placed in a support positioned at the center of the chamber. A $2.25 \mathrm{MHz}$ transducer (Imasonics, Voray-sur-l'Ognon, France) was focused (38 mm f/d=1) separately at each microplate well and single bursts of 5 cycles were transmitted by a waveform generator and amplified to $12.3 \mathrm{MPa}$ peak-negative pressure by a radio frequency amplifier[26]. 


\section{$260 \quad 2.12$ Statistical analysis}

261 The statistical analysis was performed using Statistica ${ }^{\text {TM }} 8.0$ software (StatSoft Inc., Tulsa,

262 USA). The data was analyzed by two-sided Student's $t$-test and a statistical significance 263 was set at the level of $p<0.05$. 


\section{Results and discussion}

\subsection{Synthesis and characterization of fluorinated polymers}

Polylactide polymers functionalized with either alkyl or fluorinated end-groups of five distinct lengths were synthesized by ring opening polymerization of $D, L$-lactide as described previously [32]. The end-groups are composed of linear carbon chains substituted by fluorine or hydrogen atoms; henceforth, the synthesized polymers were designated according to the terminal group chemistry and length of fluorinated unit as PLA- ${ }_{6} \mathrm{H}_{13}$, PLA$\mathrm{C}_{3} \mathrm{~F}_{7}$, PLA- $\mathrm{C}_{6} \mathrm{~F}_{13}$, PLA- $\mathrm{C}_{8} \mathrm{~F}_{17}$, PLA- $\mathrm{C}_{11} \mathrm{~F}_{23}$ and PLA- $\mathrm{C}_{13} \mathrm{~F}_{27}$.

All synthesis products were initially characterized by the presence of the lactide signals at 1.60 and $5.23 \mathrm{ppm}$ and the new ester linkage performed with the fluorinated or alkylated alcohol initiators by ${ }^{1} \mathrm{H}-\mathrm{NMR}$ (Figure 2A). As previously observed by Böhmer et al., all the fluorinated polymers exhibited a significant shift of the $-\mathrm{CH}_{2} \mathrm{O}-$ signal compared with the correspondent initiator from $4.1 \mathrm{ppm}$ to 4.55 and $4.74 \mathrm{ppm}$ (Supplementary information, Figures S1 and S2), indicating that the chemical environment of those groups were severely influenced by the PLA backbone as well as by the adjacent $\mathrm{CF}_{2}$ units [38]. Accordingly, the $-\mathrm{CH}_{2} \mathrm{O}$ - intensity was splitted into two signals with multiplicity of two triplets due to the strong coupling with both fluorine atoms and the geminal proton in the same order of magnitude $(\sim 13 \mathrm{~Hz})$, which confirmed the synthesis of fluorinated PLA polymers. Also, the fluorinated derivatives exhibited a shift of the $-\mathrm{CF}_{2} \mathrm{CH}_{2}-$ signals while other $\mathrm{CF}_{2}$ and $\mathrm{CF}_{3}$ (-78.9 to $-79.0 \mathrm{ppm}$ ) resonances were similar to each specific precursor as displayed in the ${ }^{19} \mathrm{~F}$ spectra (Figure 2B). The formation of the non-fluorinated derivative, PLA- ${ }_{6} \mathrm{H}_{13}$, was verified by the $-\mathrm{CH}_{2} \mathrm{O}$ - signal shift from 3.60 to $4.14 \mathrm{ppm}$ of the initiator.

As shown in Table 1, a relative good agreement between the experimental molar masses determined by SEC and the molar masses targeted at $20000 \mathrm{~g}^{\mathrm{mol}} \mathrm{m}^{-1}$ for all the derivatives was observed (Supplementary infromation Figure S3). The $M_{n}$ was also determined by ${ }^{1} \mathrm{H}-\mathrm{NMR}$ analysis on the basis of the integration ratio of peak at $5.23 \mathrm{ppm}$ (methine proton of lactide) and $4.55-4.74 \mathrm{ppm}$ (methylene protons adjacent to the CF chain) (Figure 2A). Slightly lower $M_{n}$ were calculated than using SEC, around $18000 \mathrm{~g}^{\mathrm{mol}}{ }^{-}$ ${ }^{1}$, which may be attributed to the difference of polymer conformation with poly(methyl methacrylate) standards.

The end-modified polymers were also characterized by DSC. They all displayed the same glass-transition temperature $\left(T_{g}\right)$, from 50 to $53^{\circ} \mathrm{C}$, similar to unmodified PLA polymers of similar molar mass (Table 1)[34, 39]. Hence, the small molecular weight endgroup did not impact the $T_{g}$ of high molar mass polylactide. 


\subsection{PFH Nanocapsules}

301

302

303

304

Fully fluorinated liquid perfluorocarbons usually display high vapor pressure values $29.1 \mathrm{kPa}$ at $25^{\circ} \mathrm{C}$ for $\mathrm{PFH}$ - and restricted solubility in organic solvents due to their fluorophilic character [40]. As a result, they tend either to phase separate or to evaporate during the formulation of nano or microcapsules by solvent emulsion-evaporation, reducing the PFC encapsulation efficacy [27, 28]. Therefore, fluorinated end-groups with distinct lengths were introduced into the PLA structure to promote "fluorous - fluorous" interactions between the polymer and liquid perfluorocarbons and enhance PFH encapsulation into nanocapsules. This strategy was shown efficient recently for a high-boiling point PFC: perfluorooctyl bromide [32]. The features of NCs formulated with fluorinated polymers, such as morphology, size, surface charge and PFH encapsulation efficiency were compared with samples produced with the non-fluorinated polymer PLA- $\mathrm{C}_{6} \mathrm{H}_{13}$.

Initial characterization demonstrated that all NC were spherical with smooth surfaces as shown by TEM and SEM images (Figure 3). The Z-average size was around $150 \mathrm{~nm}$ - in agreement with electron microscopy observations - with a negative $\zeta$-potential around -8 $\mathrm{mV}$ and a low polydispersity below 0.15 , regardless of end-group chemistry or fluorinated length as displayed in Table 2.

\section{Insert Table 2 here}

Insert Figure 3 here

Encapsulated PFH was effectively visualized by Cryo-TEM images, revealing spherical core-shell morphologies constituted by thin polymeric layers surrounding the electron-dense perfluorocarbon as shown in Figure 4 for PLA- $\mathrm{C}_{6} \mathrm{H}_{13}, \mathrm{PLA}-\mathrm{C}_{3} \mathrm{~F}_{7}, \mathrm{PLA}-\mathrm{C}_{8} \mathrm{~F}_{17}$ and PLA$\mathrm{C}_{13} \mathrm{~F}_{27}$. All samples displayed capsules containing distinct amounts of $\mathrm{PFH}$, exhibiting dark cores with a wide intensity range and also presented apparently unloaded polymeric nanoparticles, an indication of inhomogeneous encapsulation. From these images, no morphological distinction among polymer end-group chemistry or F-length was observed.

Some capsules also presented a predominant lighter core or bright spots within the perfluorocarbon phase (white arrows in Figure 4). Such areas might arise from the freezing process: as PFH retracts when it solidifies, low $\mathrm{PFH}$ densities regions appear in the capsules with probable coexistence of solid PFH (dark) with gaseous PFH (light). After 
exposure to the electron beam radiation, partial melting of the solid $\mathrm{PFH}$ occurs and light regions becomes darker (Supplementary Information, Figure S4). Those observations are consistent with Lattin et al. that reported the increased frequency of bright nanoemulsion droplets for the lower boiling point perfluoropentane $\left(\mathrm{Bp}=29^{\circ} \mathrm{C}\right)$ in comparison with perfluorohexane $\left(\mathrm{Bp}=56^{\circ} \mathrm{C}\right)$ and perfluoroheptane $\left(\mathrm{Bp}=82^{\circ} \mathrm{C}\right)$ [41] and from our own observations with PFOB [32, 42].

Insert Figure 4 here

The total encapsulated PFH was then quantified by ${ }^{19} \mathrm{~F}-\mathrm{NMR}$ for NC suspensions either freshly prepared or after freeze-drying. The samples prepared with the nonfluorinated polymer $\left(\mathrm{PLA}-\mathrm{C}_{6} \mathrm{H}_{13}\right)$ exhibited an encapsulation efficiency of $9.2 \pm 0.1 \%$ for freshly prepared suspensions and $4.0 \pm 0.5 \%$ after freeze drying, in agreement with results obtained for nanocapsules formulated with regular PLGA polymers [30]. All NC formulated with F-polymers showed a 2-fold increase in the total PFH encapsulation compared to PLA$\mathrm{C}_{6} \mathrm{H}_{13}$ as exhibited in Figure 5. A maximum encapsulation efficiency of $15 \pm 1.0 \%$ for suspensions and a $9.5 \pm 0.8 \%$ plateau for freeze-dried samples was reached, although without significant difference as a function of fluorinated chain length. Obviously, the freezedrying process induced the loss of non-encapsulated PFH droplets, as previously observed for PFOB NCs [42], although no free PFH could be observed by cryo-TEM. These results suggest a preferential interaction between fluorinated polymers and $\mathrm{PFH}$, independently of the fluorinated end-chain length, reducing the PFH loss during solvent evaporation and increasing the final encapsulation efficiency. Nonetheless, the PFH solubility and volatility still prevents higher encapsulation. Comparatively, mPEG-polycaprolactone polymers containing terminal $\mathrm{C}_{3} \mathrm{~F}_{7}$ groups were also successful in enhancing of $\mathrm{PFH}$ entrapment into NCs around $\sim 15 \%$ as reported by Li et al. [31].

Insert Figure 5 here

\subsection{In vitro cytotoxicity of NCs}

The use of fluorinated-compounds for biomedical applications is usually limited because of their persistence and consequent toxicity in the organism [43]. Indeed, the stable C-F bond hinders an effective enzymatic or metabolic degradation that results in low excretion profiles, especially for linear fluorinated compounds longer than $C_{7} F_{15}$ [44, 45]. To assess the in vitro impact of fluorinated end-groups with distinct lengths on cellular viability, NCs formulated with fluorinated polymers were incubated with two distinct cell lines, human umbilical vein endothelial (HUVEC) and murine macrophage-like (J774.A1) during 24h or 72h. The MTT assays showed that NCs did not inhibit HUVEC growth after $24 \mathrm{~h}$ or $72 \mathrm{~h}$, 
independently of NC concentration, end-group chemistry or fluorinated end-group lengths (Figure 6). For J774.A1, an inhibition down to $75 \%$ was observed for $10 \mathrm{mg} / \mathrm{mL} \mathrm{NCs}$ after $24 \mathrm{~h}$ of exposure. After $72 \mathrm{~h}$ exposure, cell viability decreased down to 75 and $50 \%$ of controls at NC concentrations of 4 and $10 \mathrm{mg} / \mathrm{mL}$, respectively (Figure 6). For both cell lines, no specific toxicity was induced due to the presence of the fluorinated groups. One should note that the reduction of cell viability of J774.A1 cells was only observed for very high NC concentrations. In addition, the distinct profiles for the two cell lines arise from the ability of J774.A1 to internalize faster and to a higher extent NCs than HUVEC [46]. Although only a limited in vitro cytotoxicity was observed, additional in vivo studies are required to investigate the effects resulting from the prolonged exposure to NCs.

\section{Insert Figure 6 here}

\subsection{In vitro Ultrasound imaging}

The imaging ability of NCs was evaluated in vitro using a plane-wave B-mode imaging system based on compounded plane-wave ultrasound transmissions[47]. All images were obtained with fixed $50 \mathrm{mg} \cdot \mathrm{mL}^{-1}$ concentrations of $\mathrm{NC}$ at $37^{\circ} \mathrm{C}$ and compared to the background gray-scale level produced by ultrapure water. At this temperature, the PFH vapor pressure increases to $48.6 \mathrm{kPa}$ - against $29.1 \mathrm{kPa}$ at $25^{\circ} \mathrm{C}$ - and potentially favors a gas-phase nucleation. Ultrasound images obtained in the conventional focused B-mode displayed a significant contrast enhancement $(p<0.001)$ arising from NC formulated with fluorinated polymers (from $1.5 \times 10^{4}$ until $5.5 \times 10^{4}$ arbitrary units, a.u.) compared to those produced with $\mathrm{PLA}-\mathrm{C}_{6} \mathrm{H}_{13}\left(0.5 \times 10^{4}\right.$ a.u.) (Figure 7). Moreover, significant differences were observed between fluorinated samples $(p<0.001)$. Additionally, the fluorinated NCs generated contrast specific echoes, enhancing the backscattering intensities from 10-fold to 40-fold higher than PLA-C ${ }_{6} \mathrm{H}_{13}$. Again, significant differences were observed between fluorinated samples except for PLA- $\mathrm{C}_{11} \mathrm{~F}_{23}$ and $\mathrm{PLA}-\mathrm{C}_{13} \mathrm{~F}_{27}$ which are not statistically different. For both ultrasound-imaging modalities, all samples exhibited long-lasting echogenicity for more than 10 minutes. As expected, Sonovue ${ }^{\circledR}$ greatly increased the ultrasound contrast compared to all NCs (from 12-fold to 35-fold) in the conventional focused B-mode and contrast specific mode due to its micrometer size and its gaseous core. In absence of PFH, the PLA- $\mathrm{C}_{8} \mathrm{~F}_{17}$ nanoparticles (NP in Figure 7) and PVA solution did not yield any significant signal enhancement.

$$
\text { Insert Figure } 7 \text { here }
$$

The acoustic enhancement observed for samples formulated with fluorinated polymers indicates that the total amount of $\mathrm{PFH}$ is a key parameter required to modulate 
398 the echogenicity of NCs, given these possess similar sizes. Interestingly, polymers 399 containing longer $F$-units, such as $P L A-C_{11} F_{23}$ and $P L A-C_{13} F_{27}$, exhibited higher 400 backscattering compared to shorter or non-fluorinated NCs. Given NC sizes are similar, 401 such variation of echogenicity with F-length might be related to an increase of NC density 402 that further affects the scattering cross section of the NCs as described in the introduction

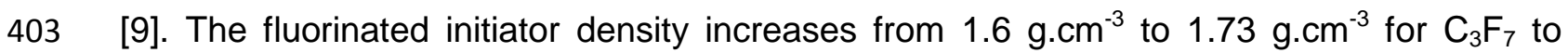
$404 \quad \mathrm{C}_{13} \mathrm{~F}_{27}$ (as provided by the supplier) whereas the density of PLA is close to the one of PLGA $405\left(1.28 \mathrm{~g} . \mathrm{cm}^{-3}\right)$ [48]. In addition, as we expect fluorinated moieties to position at the $406 \mathrm{PFH} /$ polymer interface, they might provide nuclei for PFH cavitation/bubble nucleation [49]. 407 The presence of these bubbles could also explain the harmonic response of fluorinated 408 NCs as no contrast specific signal can be observed for non-fluorinated ones (obtained with 409 PLA- $\mathrm{C}_{6} \mathrm{H}_{13}$ ) or with nanoparticles (NP, Figure 7).

At higher acoustic pressures (peak negative pressure $\sim 5 \mathrm{MPa}$ ), a signal enhancement is observed after $20 \mathrm{~ms}$ for all NCs formulated with fluorinated polymers, most probably indicating that the shell was disrupted from a certain population of capsules (as illustrated for PLA- $\mathrm{C}_{8} \mathrm{~F}_{17}$ in Figure 8). For these samples, the $\mathrm{PFH}$ is possibly completely vaporized causing the polymeric shell to shatter and allow the gas-phase to freely vibrate, which momentarily increases the echo. This transitory higher echogenicity then decreases back to the initial echogenicity as the gas bubble is dissolved or destroyed in a similar profile as observed for microbubbles [47].

Insert Figure 8 here

\subsection{PFH vaporization by focused ultrasound}

PFH-loaded NCs present an interesting potential to release chemotherapeutics inside solid tumors after local accumulation driven by the EPR effect, provided they are PEGylated and can long circulate in the blood stream. Their great advantage resides on the acoustic-sensitivity of the low boiling point PFH that can be remotely induced to vaporize by focused ultrasound (FUS) to trigger the release of co-encapsulated drug locally. To evaluate the ability of $\mathrm{PFH}$ to undergo acoustic drop vaporization under FUS, NCs were exposed to FUS acoustic pulses and analyzed morphologically by cryo-TEM.

All samples displayed a predominant population of spherical and intact NCs with core-shell morphology (Figure 9 top). However, a distinct population of capsules that exhibited deformed structures according to polymer end-chemistry were also visualized: samples produced with PLA- $\mathrm{C}_{6} \mathrm{H}_{13}$ exhibited some buckled NCs, suggesting that a partial $\mathrm{PFH}$ vaporization occurred and produced only a localized distortion of the polymeric shell. 
For NCs prepared with fluorinated polymers $-\mathrm{PLA}-\mathrm{C}_{3} \mathrm{~F}_{7}, \mathrm{PLA}-\mathrm{C}_{8} \mathrm{~F}_{17}$ and $\mathrm{PLA}-\mathrm{C}_{13} \mathrm{~F}_{27}-$ more intense shell deformations led to a complete morphological change that culminated, in many cases, in capsule disruption and observation of debris, some of them at the micrometric size range (white arrows) (Figure 9 bottom). It is important to emphasize that the focus of the ultrasonic beam is small (less than $1 \mu \mathrm{L}$ or $1 \mathrm{~mm}^{3}$ ) compared to the total volume of the samples, a factor that contributed to reduce the number of viewable debris during cryo-TEM.. The presence of PFH inside several capsules indicates that longer FUS exposition time intervals are still required for homogeneous NC disruption.

Insert Figure 9 here

Comparatively, corresponding samples were submitted to heating at $60^{\circ} \mathrm{C}$ for 10 minutes in an oil bath - above the PFH boiling point $\left(56^{\circ} \mathrm{C}\right)$. The results showed no morphological discrepancy or size variation compared to the control group (Supplementary information, Figures S5 and S6), thus suggesting that the ultrasound mechanical effects are required in addition to the thermal ones to promote a more effective vaporization as previously reported [50]. Additionally, as the temperature in focal area of FUS might become higher than $65^{\circ} \mathrm{C}$ within $1 \mathrm{~s}$ [25], the polymer shell might be above its $\mathrm{T}_{\mathrm{g}}$ of $52^{\circ} \mathrm{C}$ (Table 2) - therefore making polymer shell deformation easier.

\section{Conclusion}

We have successfully synthesized polylactide polymers containing fluorinated end-groups of different lengths, from $\mathrm{C}_{3} \mathrm{~F}_{7}$ until $\mathrm{C}_{13} \mathrm{~F}_{27}$ that were formulated into nanocapsules containing a perfluorohexane core. The employment of fluorinated polymers increased by 2-fold the encapsulation efficiency of perfluorohexane into nanocapsules, although no effect of fluorine chain length was observed. Fluorination of the polymers did not induce any specific in vitro cytotoxicity towards HUVEC and J774.A1 cell lines. Nanocapsules formulated with fluorinated polymers enhanced their acoustic response compared to PLA$\mathrm{C}_{6} \mathrm{H}_{13}$ in both fundamental and harmonic ultrasound imaging modalities. An increased echogenicity and harmonic response was observed as the fluorinated chain-length increased, probably due to an increase of density and promotion of bubble nucleation. When submitted to focused ultrasound, both intact and exploded nanocapsules could be observed, also with end-group dependency, indicating that the perfluorocarbon was partly vaporized. These results pave the way to theranostic perfluorohexane nanocapsules coencapsulating a drug for precision delivery using focused ultrasound. 


\section{Acknowledgements}

467 Authors would like to thank Mehrez Sghaier and Najet Yagoubi from Laboratoire Matériaux 468 et Santé (EA401, Univ. Paris-Sud) for DSC experiments and Stéphanie Denis (Institut 469 Galien Paris-Sud) for her help with cell culture. This work has been supported by the 470 Region lle-de-France in the framework of DIM Nano-K (France) and by Conselho Nacional 471 de Desenvolvimento Científico e Tecnológico (CNPq, Brazil). The present work has 472 benefited also from the core facilities of Imagerie-Gif, (http://www.i2bc.paris-saclay.fr), 473 member of IBiSA (http://www.ibisa.net), supported by "France-Biolmaging" (ANR-10-INBS474 04-01), and the Labex "Saclay Plant Science" (ANR-11-IDEX-0003-02). Authors 475 acknowledge financial support from ANR (Investissements d'Avenir, Nanobiotechnologies, 476 ANR-10-NANO-06-04). Institut Galien Paris-Sud is a member of the Laboratory of 477 Excellence LERMIT supported by a grant from ANR (ANR-10-LABX-33). 


\section{6- References}

480 [1] Chang EH, Chong WK, Kasoji SK, Dayton PA, Rathmell WK. Management of Indeterminate Cystic Kidney Lesions: Review of Contrast-enhanced Ultrasound as a Diagnostic Tool. Urology 2016;87:110.

483

484

485

486

487

488

489

490

491

492

493

494

495

496

497

498

499

500

501

502

503

504

505

506

507

508

509

510

[2] Kaul S, Ito H. Microvasculature in Acute Myocardial Ischemia: Part I. Evolving Concepts in Pathophysiology, Diagnosis, and Treatment 2004;109:146-9.

[3] Quaia E, Calliada F, Bertolotto M, Rossi S, Garioni L, Rosa L, Pozzi-Mucelli R. Characterization of Focal Liver Lesions with Contrast-specific US Modes and a Sulfur Hexafluoride-filled Microbubble Contrast Agent: Diagnostic Performance and Confidence. Radiology 2004;232:420-30.

[4] Borden MA, Martinez GV, Ricker J, Tsvetkova N, Longo M, Gillies RJ, Dayton PA, Ferrara KW. Lateral Phase Separation in Lipid-Coated Microbubbles. Langmuir 2006;22:4291-7.

[5] Dalvi SV, Joshi JR. Modeling of microbubble dissolution in aqueous medium. Journal of Colloid and Interface Science 2015;437:259-69.

[6] Schneider M. Characteristics of SonoVue(TM). Echocardiography 1999;16:743-6.

[7] Leroy V, Norisuye T. Investigating the Existence of Bulk Nanobubbles with Ultrasound. Chemphyschem 2016;17:2787-90.

[8] Cosco D, Fattal E, Fresta M, Tsapis N. Perfluorocarbon-loaded micro and nanosystems for medical imaging: A state of the art. Journal of Fluorine Chemistry 2015;171:18-26.

[9] Dejong N, Tencate FJ, Lancee CT, Roelandt JRTC, Bom N. Principles and Recent Developments in Ultrasound Contrast Agents. Ultrasonics 1991;29:324-30.

[10] Duncanson WJ, Arriaga LR, Ung WL, Kopechek JA, Porter TM, Weitz DA. Microfluidic Fabrication of Perfluorohexane-Shelled Double Emulsions for Controlled Loading and AcousticTriggered Release of Hydrophilic Agents. Langmuir 2014;30:13765-70.

[11] Kripfgans OD, Fowlkes JB, Miller DL, Eldevik OP, Carson PL. Acoustic droplet vaporization for therapeutic and diagnostic applications. Ultrasound in Medicine \& Biology 2000;26:1177-89.

[12] Ken-ichi K, Nami S, Hideki Y, Takashi A, Shin-ichiro U. Nanoparticles with Multiple Perfluorocarbons for Controllable Ultrasonically Induced Phase Shifting. Japanese Journal of Applied Physics 2005;44:4548.

[13] Rapoport N, Nam K-H, Gupta R, Gao Z, Mohan P, Payne A, Todd N, Liu X, Kim T, Shea J, Scaife C, Parker DL, Jeong E-K, Kennedy AM. Ultrasound-mediated tumor imaging and nanotherapy using drug loaded, block copolymer stabilized perfluorocarbon nanoemulsions. Journal of Controlled Release 2011;153:4-15. 
[14] Sheeran PS, Luois SH, Mullin LB, Matsunaga TO, Dayton PA. Design of ultrasonically-activatable nanoparticles using low boiling point perfluorocarbons. Biomaterials 2012;33:3262-9.

[15] Shpak O, Verweij M, Vos HJ, de Jong N, Lohse D, Versluis M. Acoustic droplet vaporization is initiated by superharmonic focusing. Proceedings of the National Academy of Sciences 2014;111:1697-702.

[16] Guédra M, Coulouvrat F. A model for acoustic vaporization of encapsulated droplets. J Acoust Soc Am 2015;138:3656-67.

[17] Boissenot T, Fattal E, Bordat A, Houvenagel S, Valette J, Chacun H, Gueutin C, Tsapis N. Paclitaxel-loaded PEGylated nanocapsules of perfluorooctyl bromide as theranostic agents. European Journal of Pharmaceutics and Biopharmaceutics 2016;108:136-44.

[18] Maeda H. Vascular permeability in cancer and infection as related to macromolecular drug delivery, with emphasis on the EPR effect for tumor-selective drug targeting. P Jpn Acad B-Phys 2012;88:53-71.

[19] Diou O, Tsapis N, Giraudeau C, Valette J, Gueutin C, Bourasset F, Zanna S, Vauthier C, Fattal E. Long-circulating perfluorooctyl bromide nanocapsules for tumor imaging by 19FMRI. Biomaterials 2012;33:5593-602.

[20] Diou O, Fattal E, Delplace V, Mackiewicz N, Nicolas J, Meriaux S, Valette J, Robic C, Tsapis N. RGD decoration of PEGylated polyester nanocapsules of perfluorooctyl bromide for tumor imaging: Influence of pre or post-functionalization on capsule morphology. European Journal of Pharmaceutics and Biopharmaceutics 2014;87:170-7.

[21] Danhier F. To exploit the tumor microenvironment: Since the EPR effect fails in the clinic, what is the future of nanomedicine? Journal of Controlled Release 2016;244:108-21.

[22] Singh R, Husseini GA, Pitt WG. Phase transitions of nanoemulsions using ultrasound: Experimental observations. Ultrason Sonochem 2012;19:1120-5.

[23] Clark AJ, Wiley DT, Zuckerman JE, Webster P, Chao J, Lin J, Yen Y, Davis ME. CRLX101 nanoparticles localize in human tumors and not in adjacent, nonneoplastic tissue after intravenous dosing. P Natl Acad Sci USA 2016;113:3850-4.

[24] Uchida T, Tomonaga T, Kim H, Nakano M, Shoji S, Nagata Y, Terachi T. Improved Outcomes with Advancements in High Intensity Focused Ultrasound Devices for the Treatment of Localized Prostate Cancer. The Journal of Urology 2015;193:103-10.

[25] You YF, Wang ZG, Ran HT, Zheng YY, Wang D, Xu JS, Wang ZB, Chen Y, Li P. Nanoparticleenhanced synergistic HIFU ablation and transarterial chemoembolization for efficient cancer therapy. Nanoscale 2016;8:4324-39.

[26] Bezagu M, Errico C, Chaulot-Talmon V, Monti F, Tanter M, Tabeling P, Cossy J, Arseniyadis S, Couture O. High spatiotemporal control of spontaneous reactions using ultrasound-triggered composite droplets. Journal of the American Chemical Society 2014;136:7205-8. 
[27] Pisani E, Fattal E, Paris J, Ringard C, Rosilio V, Tsapis N. Surfactant dependent morphology of polymeric capsules of perfluorooctyl bromide: Influence of polymer adsorption at the dichloromethane-water interface. Journal of Colloid and Interface Science 2008;326:66-71.

[28] Mousnier L, Huang N, Morvan E, Fattal E, Tsapis N. Influence of polymer end-chemistry on the morphology of perfluorohexane polymeric microcapsules intended as ultrasound contrast agents. International journal of pharmaceutics 2014;471:10-7.

[29] Koda Y, Terashima T, Sawamoto M. Fluorinated Microgels in Star Polymers: From In-Core Dynamics to Fluorous Encapsulation. Macromolecules 2015;48:2901-8.

[30] Srinivas M, Cruz LJ, Bonetto F, Heerschap A, Figdor CG, de Vries IJM. Customizable, multifunctional fluorocarbon nanoparticles for quantitative in vivo imaging using F-19 MRI and optical imaging. Biomaterials 2010;31:7070-7.

[31] Li H, Wang J, Wang P, Zheng J, Song F, Yin T, Zhou G, Zheng R, Zhang C. Phase-transition contrast nanocapsules triggered by low-intensity ultrasound. Chemical Communications 2014;50:15163-6.

[32] Houvenagel S, Picheth G, Dejean C, Brulet A, Chenneviere A, Couture O, Huang N, Moine L, Tsapis N. End-chain fluorination of polyesters favors perfluorooctyl bromide encapsulation into echogenic PEGylated nanocapsules. Polymer Chemistry 2017;8:2559-70.

[33] Singh A, Naskar AK, Haynes D, Drews MJ, Smith DW. Synthesis, characterization and surface properties of poly(lactic acid)-perfluoropolyether block copolymers. Polymer International 2011;60:507-16.

[34] Giuntoli G, Rosi L, Frediani M, Sacchi B, Frediani P. Fluoro-functionalized PLA polymers as potential water-repellent coating materials for protection of stone. Journal of Applied Polymer Science 2012;125:3125-33.

[35] Henderson TJ. Quantitative NMR Spectroscopy Using Coaxial Inserts Containing a Reference Standard: Purity Determinations for Military Nerve Agents. Analytical Chemistry 2002;74:191-8.

[36] Gerlier D, Thomasset N. Use of MTT colorimetric assay to measure cell activation. J Immunol Methods 1986;94:57-63.

[37] Couture O, Bannouf S, Montaldo G, Aubry J-F, Fink M, Tanter M. Ultrafast Imaging of Ultrasound Contrast Agents. Ultrasound in Medicine \& Biology 2009;35:1908-16.

[38] Böhmer MR, Schroeders R, Steenbakkers JAM, de Winter SHPM, Duineveld PA, Lub J, Nijssen WPM, Pikkemaat JA, Stapert HR. Preparation of monodisperse polymer particles and capsules by ink-jet printing. Colloids and Surfaces A: Physicochemical and Engineering Aspects 2006;289:96104.

[39] Chen C-C, Chueh J-Y, Tseng H, Huang H-M, Lee S-Y. Preparation and characterization of biodegradable PLA polymeric blends. Biomaterials 2003;24:1167-73. 
[40] West KN, Hallett JP, Jones RS, Bush D, Liotta CL, Eckert CA. CO2-Induced Miscibility of Fluorous and Organic Solvents for Recycling Homogeneous Catalysts. Industrial \& Engineering Chemistry Research 2004;43:4827-32.

[41] Lattin JR, Belnap DM, Pitt WG. Formation of eliposomes as a drug delivery vehicle. Colloid Surface B 2012;89:93-100.

[42] Diou O, Brûlet A, Pehau-Arnaudet G, Morvan E, Berti R, Astafyeva K, Taulier N, Fattal E, Tsapis N. PEGylated nanocapsules of perfluorooctyl bromide: Mechanism of formation, influence of polymer concentration on morphology and mechanical properties. Colloids and Surfaces B: Biointerfaces 2016;146:762-9.

[43] Riess JG. Highly fluorinated amphiphilic molecules and self-assemblies with biomedical potential. Curr Opin Colloid In 2009;14:294-304.

[44] Zaggia A, Ameduri B. Recent advances on synthesis of potentially non-bioaccumulable fluorinated surfactants. Curr Opin Colloid In 2012;17:188-95.

[45] Barmentlo SH, Stel JM, van Doom M, Eschauzier C, de Voogt P, Kraak MHS. Acute and chronic toxicity of short chained perfluoroalkyl substances to Daphnia magna. Environ Pollut 2015;198:4753.

[46] Reul R, Tsapis N, Hillaireau H, Sancey L, Mura S, Recher M, Nicolas J, Coll JL, Fattal E. Near infrared labeling of PLGA for in vivo imaging of nanoparticles. Polymer Chemistry 2012;3:694-702.

[47] Couture O, Fink M, Tanter M. Ultrasound contrast plane wave imaging. IEEE Trans Ultrason Ferroelectr Freq Control 2012;59:1.

[48] Astafyeva K, Thomas JL, Coulouvrat F, Guedra M, Diou O, Mousnier L, Tsapis N, Urbach W, Taulier N. Properties of theranostic nanoparticles determined in suspension by ultrasonic spectroscopy. Phys Chem Chem Phys 2015;17:25483-93.

[49] Choi C-H, David M, Gao Z, Chang A, Allen M, Wang H, Chang C-h. Large-scale Generation of Patterned Bubble Arrays on Printed Bi-functional Boiling Surfaces. Sci Rep 2016;6:23760.

[50] Novell A, Al Sabbagh C, Escoffre J-M, Gaillard C, Tsapis N, Fattal E, Bouakaz A. Focused ultrasound influence on calcein-loaded thermosensitive stealth liposomes. International Journal of Hyperthermia 2015;31:349-58. 
Table 1. Number-average molar masses $(\mathrm{Mn})$ obtained by SEC/1H-NMR, dispersity and glasstransition temperature $(\mathrm{Tg})$ of all synthesized polymers.

615

Table 2. Z-average size, polydispersity index and Z-potential for nanocapsules formulated with fluorinated and non-fluorinated polymers. Data are presented as mean $\pm S D(n=3)$.

618

Figure 1: Schematic representation (A) and real view (B) of the US set-up.

620

Figure 2. $1 \mathrm{H}-\mathrm{NMR}$ spectra of all synthesized polymers with enlargement of the corresponding lactide and ester linkage signals (A). Magnified CF3 and CF2 regions in the 19F spectra for PLA-C3F7, PLA-C6F13, PLA-C8F17, PLA-C11F23 and PLA-C13F27 (B). The 1H and 19F peak assignments are indicated in the insert. All samples were dissolved in $\mathrm{CDCl} 3$.

625

Figure 3. Transmission (left) and scanning electron microscopy images (right) for nanocapsules formulated with fluorinated and non-fluorinated polymers.

Figure 4. Cryo-TEM images of nanocapsules formulated with fluorinated PLA-C3F7, PLA-C8F17 and PLA-C13F27 as well as non-fluorinated PLA-C6H13 polymers. The white arrows show the bright regions within the nanocapsules.

632

Figure 5. PFH encapsulation efficiency for NCs freshly prepared suspension (red bars) or submitted to freeze-drying (blue bars).

635

Figure 6. Cell viability as a function of NC concentration for HUVEC (top) and J774.A1 (bottom) at $24 \mathrm{~h}$ (left) and $72 \mathrm{~h}$ (right). All results are presented as mean $\pm \mathrm{SD}(\mathrm{N}=2)$.

638

Figure 7. Ultrasound backscattered intensity at the conventional focused B-mode (black symbols) and contrast specific (red symbols) modalities for PVA, nanoparticles of PLA-

$641 \mathrm{C}_{8} \mathrm{~F}_{17}$ (NP) and all formulated nanocapsules. The error bars represent the ultrasound signal 642 variability between the echo-pulses for each sample (about $5 \%$ error). Differences between $643 \mathrm{NC}$ formulated with fluorinated polymers and those produced with $\mathrm{PLA}-\mathrm{C}_{6} \mathrm{H}_{13}$ were 644 statistically significant in both modes. Moreover, significant differences were observed 
645 between fluorinated samples in conventional mode $(p<0.001)$. In contrast specific imaging 646 Again, significant differences were observed between fluorinated samples except for PLA$647 \mathrm{C}_{11} \mathrm{~F}_{23}$ and PLA- $\mathrm{C}_{13} \mathrm{~F}_{27}$ which are not statistically different.

648

649

650 Figure 8. Sequential ultrasonic images of PLA-C8F17 nanocapsules prior (-200 ms) and after 651 exposure to FUS (from 20 to $1000 \mathrm{~ms}$ ). The average amplitude signal is presented for each image 652 (bottom). The scale bar corresponds to $1 \mathrm{~mm}$.

653

654 Figure 9. Cryo-TEM images of nanocapsules after focused ultrasound exposure. Intact/spherical 655 (top) and buckled or debris of nanocapsules (bottom) were observed for all samples. All scale bars 656 represent $100 \mathrm{~nm}$.

657 